Article

\title{
Development and Application of a Spiritual Well-Being Questionnaire Called SHALOM
}

\author{
John Fisher ${ }^{1,2}$
}

1 School of Education, University of Ballarat, Victoria 3350, Australia; E-Mail: j.fisher@ballarat.edu.au; Tel.: +61-3-5320-3531; Fax: +61-3-5320-3763

2 School of Rural Health, Faculty of Medicine, University of Melbourne, Victoria 3350, Australia; E-Mail: jwfisher@unimelb.edu.au

Received: 11 November 2010; in revised form: 29 November 2010 / Accepted: 6 December 2010 / Published: 9 December 2010

\begin{abstract}
The Four Domains Model of Spiritual Health and Well-Being was used as the theoretical base for the development of several spiritual well-being questionnaires, with progressive fine-tuning leading to the Spiritual Health And Life-Orientation Measure (SHALOM). SHALOM comprises 20 items with five items reflecting the quality of relationships of each person with themselves, other people, the environment and/or God, in the Personal, Communal, Environmental and Transcendental domains of spiritual well-being. SHALOM has undergone rigorous statistical testing in several languages. SHALOM has been used with school and university students, teachers, nurses, medical doctors, church-attenders, in industry and business settings, with abused women, troubled youth and alcoholics. SHALOM provides a unique way of assessing spiritual well-being as it compares each person's ideals with their lived experiences, providing a measure of spiritual harmony or dissonance in each of the four domains.
\end{abstract}

Keywords: spiritual well-being; assessment; SHALOM; spiritual dissonance

\section{Introduction}

It is not easy working out how to assess spiritual well-being (SWB). Like the fictional character Superman, who has the legendary ability to leap over tall buildings in a single bound, some researchers have attempted to employ a single question to capture the essence of this complex construct $[1,2]$. One such study defined spirituality as 'personal beliefs in God or a higher power' [3]. These authors 
criticized their own single-item measure and their 'theistic conceptualization' of spirituality, concluding 'The scientific community must seek to produce indicators to accurately reflect how youth experience spirituality in their own lives, rather than trying to categorize them according to outdated indicators of "religiosity".'

Many attempts at assessing spirituality and spiritual health/well-being ( $\mathrm{SH} / \mathrm{WB}$ ) reported in the literature range from single item measures to one with 156 items [4-11]. It is difficult to make sense of this wide diversity of research because the conceptual bases upon which the research is founded vary markedly between studies [12].

Much of the research confounds spirituality and religion. Although there are commonalities between these two constructs, many authors agree they are not synonymous [6-8,13-18]. Researchers must attempt to remain aloof from their personal world-views as far as they possibly can so as not to allow their ideologies to constrain research projects associated with SWB, e.g., privilege religion or deny its relevance to some people. All measurement devices are built on a values base (generally the researcher's), and most instruments present norms for populations studied. Norms vary so much between groups that what appears to be positive for SWB in one group might have negative implications in another. Furthermore, each group believes that its own criteria for 'true' spirituality is better than everyone else's and should possibly be the normative base for all humanity. Investigating spirituality is complicated because any measure cannot be perfect, and it only reflects the phenomenon or its consequences, because it cannot be measured directly [7].

Most measures are self-reports, but they might not reflect reality, because "feeling well is not necessarily being well". It is essential to check the validity of any instrument used. Does it "genuinely measure spirituality or its components?"[7]. The power of a questionnaire depends on its theoretical base and the rigor with which it is developed and tested [18].

Nearly all available religiosity/spirituality measures ask people for a single response about 'lived experience' on a series of questions [19]. In the best instruments, these questions are built on theoretical frameworks of relationships between spirituality and health that are considered important by the developers of the scales. The 'scores' thus obtained are limited indicators of spiritual health or well-being, especially if they only have a handful of items [20]. As mentioned above, the notion of a group norm of spiritual health is also problematic. People's spiritual health depends on their world-view and beliefs as well as lived experience [14,21], so development of a single measure, which purports to be an objective standard by which to compare people, challenges the multifaceted nature of spiritual health.

A clear conceptual foundation is needed upon which to develop a sound measure of SWB. The Spiritual Well-Being Survey (SWBS) is a commonly used instrument in the U.S., comprising two 10-item measures, one for Existential Well-Being, the other for Religious Well-Being (RWB) [22]. This scale was considered too God-oriented for use with increasingly secular Australians, although it was used to validate SHALOM during its development. Some factor analyses on the SWBS have questioned the validity of the proposed factor structure for differing populations [23,24] and ceiling effects have been noted, especially for the RWB factor among highly religious groups [25]. Nevertheless, the SWBS had been used in 182 studies by 2007 [26]. 


\section{Four Domains Model of Spiritual Health and Well-Being (4D model of SH/WB)}

Ellison suggested that spiritual well-being "arises from an underlying state of spiritual health and is an expression of it, much like the color of one's complexion and pulse rate are expressions of good [physical] health" [22]. Fehring, Miller and Shaw supported this view by adding "spiritual well-being is an indication of individuals' quality of life in the spiritual dimension or simply an indication of their spiritual health" [27].

Although Ellison only used two facets of SWB in the SWBS, four main themes appear in the framework definition of spiritual well-being proposed by the National Interfaith Coalition on Aging (NICA), in Washington DC: "the affirmation of life in a relationship with God, self, community and environment that nurtures and celebrates wholeness" [28]. An extensive review of literature revealed that these four sets of relationships are the key features mentioned when discussing spiritual well-being over the last three decades [15,19,22,29-31]. Detailed descriptions of these four domains of spiritual health were developed from interviews with 98 educators from 22 secondary schools (State, Catholic and Independent) in Victoria, Australia, together with surveys from 23 Australian experts [21]. The following definition was derived, in which spiritual health is described as:

A, if not the, fundamental dimension of people's overall health and well-being, permeating and integrating all the other dimensions of health (i.e., physical, mental, emotional, social and vocational). Spiritual health is a dynamic state of being, shown by the extent to which people live in harmony within relationships in the following domains of spiritual well-being:

Personal domain - wherein one intra-relates with oneself with regards to meaning, purpose and values in life. Self-awareness is the driving force or transcendent aspect of the human spirit in its search for identity and self-worth.

Communal domain - as shown in the quality and depth of interpersonal relationships, between self and others, relating to morality, culture and religion. These are expressed in love, forgiveness, trust, hope and faith in humanity.

Environmental domain - beyond care and nurture for the physical and biological, to a sense of awe and wonder; for some, the notion of unity with the environment.

Transcendental domain - relationship of self with some-thing or some-One beyond the human level (i.e., ultimate concern, cosmic force, transcendent reality or God). This involves faith towards, adoration and worship of, the source of Mystery of the universe [21].

This definition outlines the inter-connective and dynamic nature of spiritual health, in which internal harmony depends on intentional self-development, coming from congruence between expressed and experienced meaning, purpose and values in life at the Personal level. This intentional self-development often eventuates from personal challenges, which go beyond contemplative meditation, leading to a state of bliss, perceived by some as internal harmony.

Morality, culture and religion are included in the Communal domain of spiritual health, in accord with Tillich's view that the three interpenetrate, constituting a unity of the spirit, but "while each element is distinguishable, they are not separable" [32]. In the work presented here, religion (with small ' $r$ ') is construed as essentially a human, social activity with a focus on ideology and rules (of 
faith and belief systems), as distinct from a relationship with a Transcendent Other such as that envisioned in the Transcendental domain of spiritual health. Whilst it is acknowledged that the ideals of most religions would embrace relationships with both horizontal and vertical aspects, the two are separated for emphasis in this model.

\section{Development of Measures}

A search in 2009 revealed nearly 190 quantitative measures of spirituality and/or Spiritual Health/Well-Being (SH/WB) in available literature published since 1967 [33]. These have been critiqued in light of the four domains model of spiritual health and well-being. Many more religiosity measures have also been reported [4,5]. Measures based directly upon the 4D model of SH/WB include two measures:

\subsection{Spiritual Health in Four Domains Index (SH4DI)}

The Spiritual Health in Four Domains Index (SH4DI) was developed by overlaying the 4D model of SH/WB on a selection from 150 items used to study spirituality among 311 primary teachers in the UK [34]. Exploratory factor analyses were used to establish four factors in the SH4DI, each comprised of six items, with response sets on a 5-point Likert scale. Another study of mainly pastoral carers (in 1998) in a variety of Victorian schools led to a refinement of the SH4DI, by introducing two levels of response for each item [35]. This study contained eight items representing each of the four domains with 5-point Likert scales (ranging from 'very high' to 'very low').

\subsection{Spiritual Health And Life-Orientation Measure (SHALOM)}

The title SHALOM was chosen to represent the very essence of SWB. The Hebrew word Shalom means "completeness, wholeness, health, peace, welfare, safety, soundness, tranquility, prosperity, fullness, rest, harmony, the absence of agitation or discord" [36]. The acronym SHALOM reveals its two components - Spiritual Health measure (SHM) And Life-Orientation Measure (LOM). The LOM elicits the 'ideals' people have for SH in four sets of relationships with self, others, environment and/or God. The SHM asks people to reflect on 'lived experience/how they feel each item reflects their personal experience most of the time.'

SHALOM was developed in the belief that an instrument based on input from 850 secondary school students with diverse cultural and religious backgrounds should have appropriate language and conceptual clarity for studies of SWB within general populations and individuals, from teens to the twilight years [37]. An initial selection of 60 items derived from the 4D model of spiritual health was reduced to the 20-item SHALOM using exploratory factor analysis (Table 1). The five items in each of four domains of SH were scored using Likert scale responses from $1=$ very low to $5=$ very high: 
Table 1. Items comprising four domains of spiritual well-being in SHALOM.

\begin{tabular}{l|l}
\hline Personal & Communal \\
\hline sense of identity & $\begin{array}{l}\text { love of other people } \\
\text { forgiveness toward others } \\
\text { self-awareness } \\
\text { joy in life } \\
\text { inner peace } \\
\text { meaning in life }\end{array}$ \\
\hline Environmental & $\begin{array}{l}\text { respect for others } \\
\text { kindness toward other people }\end{array}$ \\
\hline connection with nature & Transcendental \\
awe at a breathtaking view & personal relationship with the Divine/God \\
oneness with nature & worship of the Creator \\
harmony with the environment & oneness with God \\
sense of 'magic' in the environment & peace with God \\
\hline
\end{tabular}

The 'lived experience' component of SHALOM has been extensively tested and reported as the Spiritual Well-Being Questionnaire (SWBQ) [38-40]. In hindsight, it would have been better to have referred to this part of SHALOM as the Spiritual Health Measure to avoid any potential confusion with Moberg's instrument called SWBQ, which has 42-items distributed across 7-factors [41]. Some confusion could also possibly occur with Ellison's Spiritual Well-Being Survey (SWBS) [22], which shares three quarters of its name with the SWBQs.

Confirmatory factor analyses were performed on the SWBQ using data from 4462 nurses and carers, university students and staff, school students and teachers, employees in a manufacturing plant and church-attendees. The SWBQ showed good reliability (Cronbach's alpha, composite reliability and variance extracted) as well as (construct, concurrent, discriminant, predictive) validity [38]. Factorial independence from personality shown by the SWBQ indicates that it does more than just 'religify' existing personality constructs [Van Wicklin, cited in 42]. Some researchers have tried to equate spiritual well-being with mental well-being [43,44]. However, Rowold has recently provided evidence that the German version of the SWBQ/SHALOM scales are independent of mental, as well as physical and emotional well-being, adding to our 'knowledge about the validity of the construct of spiritual well-being' [45]. The stringent process applied to the development of SWBQ/SHALOM yielded salient features of each of the domains to make the overall instrument a balanced, sensitive, flexible tool for assessing spiritual health and well-being, tapping into features beyond mental, emotional and physical well-being.

With only 20 items, SWBQ/SHALOM cannot be considered an exhaustive measure of SH/WB. If carers and clients have time, as well as confidential relationships, it is possible to use suitable qualitative procedures to mine the depths of people's SH/WB [46]. Rather than taking considerable time for an in-depth qualitative assessment, possibly hours, in 5-10 minutes, plus five minutes scoring time, the SWBQ/SHALOM provides an effective means of indicating key aspects of these four domains of $\mathrm{SH} / \mathrm{WB}$.

Some people believe that a wholesome relationship with oneself is all that is necessary for SH/WB [47]. Other people believe that you can only truly be yourself in relation with others [48]. 
Increasing numbers of Westerners are beginning to note what has been recognized by Indigenous peoples and many Easterners for some time, in that it is important to relate with the environment not only for sustenance but also for the well-being of humanity. Relating with a Transcendent Other/God is considered part of, but not restricted to, religious practice. Some studies have introduced terms such as 'higher power' to replace 'God' in attempts to be more inclusive and/or less offensive to non-theists [49]. In the development of SHALOM, terms such as 'godlike force' and 'supernatural power' were trialed but found wanting as they were not meaningful to teenagers (and therefore a range of adults?). Whether theistic, or not, nearly all people have a concept of 'God.' As they compare their ideals with their lived experience, it is up to each person to define their own meaning for each notion under investigation. For example, many different religions and denominations exist because of people's differing views. A brief question about religion is asked in the demographic section of the author's surveys, along with gender and age, but religion per se is not included in the SWBQ/SHALOM.

In a recent review of 'ten questionnaires that address spirituality as a universal human experience', the SWBQ was judged to be the only instrument that had proven validity and reliability and was promising for easy administration in clinical nursing investigations [50].

\section{Applications of the Spiritual Well-Being Questionnaire}

All people requesting a copy of the SH4DI or the SWBQ/SHALOM are sent a copy of SHALOM, with references to the theoretical model underpinning it, and papers describing its application, together with a scoring key. The 'cost' of receiving this material from the author is agreement to provide comments on the instrument's usefulness. One hundred and nine requests had been received by the author by mid-2010. From August to October up to three follow-up E-mails were sent to each recipient requesting minimal information on the usefulness of SHALOM, together with a copy of any relevant publication/s. The following transpired:

(a). Twenty of the recipients were no longer available at the stated e-mail address (15 of these were university students or staff no longer at the institutions).

(b). Fifteen people did not reply to any of the e-mails, even though their addresses still seemed to be 'active.'

(c). Twenty-eight of the people requesting the instrument did not use it due to a variety of reasons: seven because the projects changed and two because they were cancelled; four used the information for reference only; one withdrew due to ill health; one could not use it because of 'separation of church and state' issues in public schools in the U.S.; one could not see any way of changing current practice in her health service; one thought it was not suitable for use with old people in Scotland (although SHALOM has been successfully used elsewhere with people aged into their 80 s), one reported undefined difficulties by 11-13 year-olds in the U.S. (in spite of successful use in Australia with this age group [51,52] and even with 8-12 year-olds in Canada [53]), a Thai person wanted to use a specifically Thai instrument and two studies with Indigenous people (New Zealand and Canada) wanted more culturally-specific content (even though there has been a successful Canadian study using the SWBQ with First Nations people [54]). The main problem with 
using a particular measure is that the results cannot be compared with other research or groups. Moberg has emphasized the need to 'combine particularistic and universal strategies for clinical assessments and scientific research' in SWB [7]. The SWBQ/SHALOM provides a valuable base for the universal study of SH/WB. Points of particular concern are easily employed in auxiliary questions, e.g., in questioning ways in which SWB is enhanced, items can include ancestor worship, importance of place, totem, sacred writings, symbols or rituals, etc. The item scores can then be correlated with the four SH/WB domain scores, and gender, personality, happiness, etc and for comparison between groups.

(d). Four people used the material as a basis for developing their own research procedures and/or instruments.

(e). Work is still in progress, with no reports yet from 19 of the studies.

(f). Reports were received from 23 researchers. Three of these researchers only reported $\alpha$-values for the four domains of SH/WB and/or correlation values with personality and marital satisfaction, but not mean values for domain scores.

As many researchers seem constrained by the notion of norms, mean values for the four domains of SWB (plus SD where available) from the above studies, together with 10 from the author, are listed in the following tables. Care should be taken in interpreting these data as they do not claim to be representative of the populations studied and some sub-groups are small in size.

Although SHALOM was developed for use with secondary school students and adults, a Canadian study reports its effective use in a study of SWB and happiness with primary school children aged eight to 12 years [53]. The papers referenced in Table 2 provide discussion of the variations between groups of students and staff.

Table 2. SWB levels among school students and staff using the SWBQ.

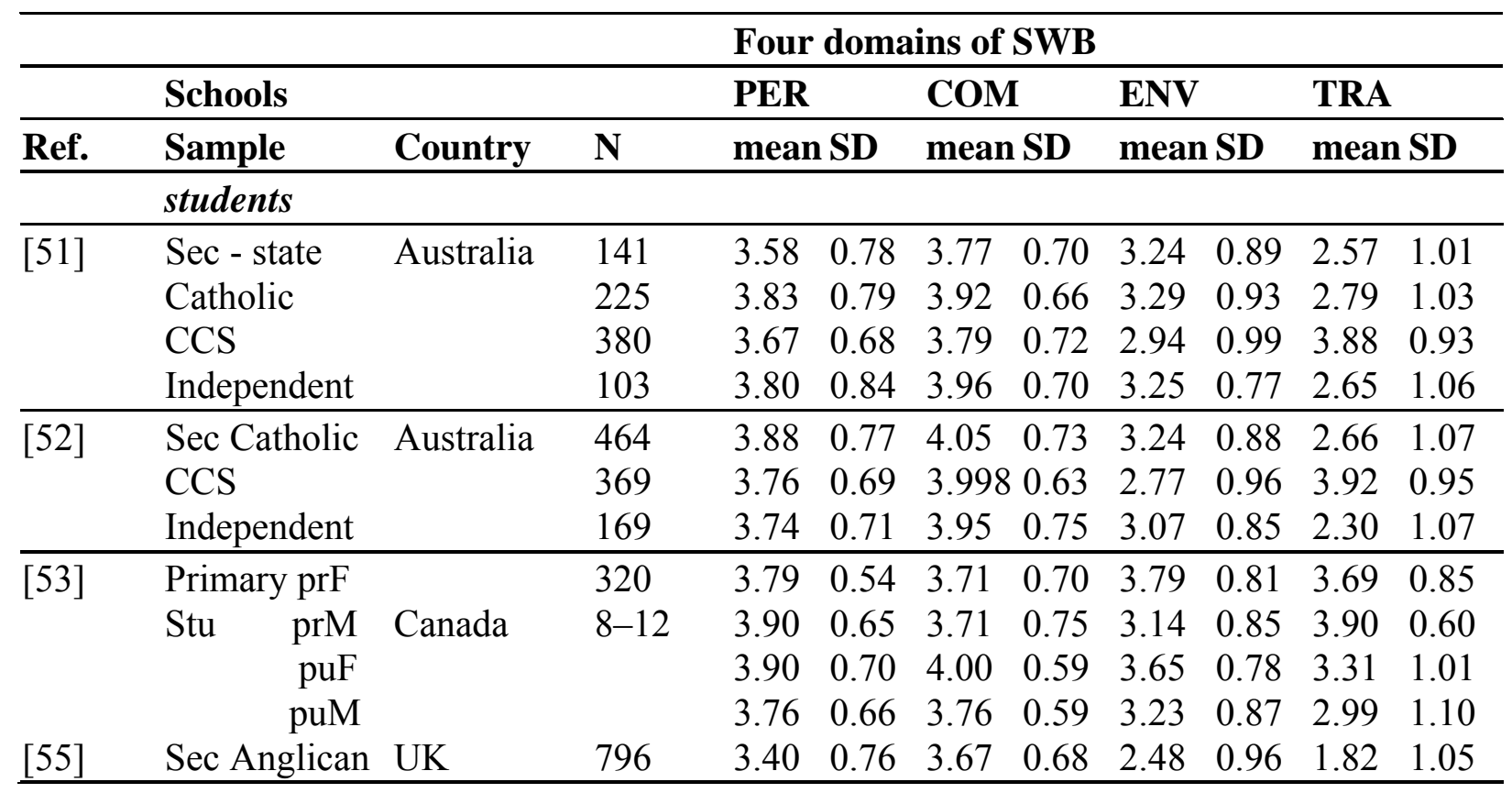


Table 2. Cont.

\begin{tabular}{|c|c|c|c|c|c|c|c|c|c|c|c|}
\hline & staff & & & & & & & & & & \\
\hline [56] & Pre-schl trs & Hong Kong & 146 & 3.92 & 0.62 & 3.97 & 0.57 & 3.68 & 0.63 & 3.30 & 0.97 \\
\hline \multirow[t]{3}{*}{ [35] } & TeacherState & Australia & 41 & 3.87 & 0.58 & 4.09 & 0.67 & 3.10 & 0.83 & 2.54 & 1.08 \\
\hline & Independent & & 53 & 4.06 & 0.62 & 4.21 & 0.59 & 3.29 & 0.77 & 3.58 & 1.07 \\
\hline & Catholic & & 49 & 4.34 & 0.52 & 4.41 & 0.47 & 3.72 & 0.67 & 3.89 & 0.75 \\
\hline \multirow[t]{4}{*}[57]{} & TeacherState & Australia & 68 & 4.18 & 0.64 & 4.36 & 0.59 & 3.81 & 0.91 & 2.32 & 1.28 \\
\hline & Independent & & 253 & 4.07 & 0.64 & 4.24 & 0.60 & 3.64 & 0.85 & 3.40 & 1.19 \\
\hline & Catholic & & 163 & 4.17 & 0.59 & 4.33 & 0.53 & 4.02 & 0.70 & 3.59 & 0.92 \\
\hline & $\mathrm{CCS}$ & & 335 & 4.01 & 0.57 & 4.15 & 0.54 & 3.21 & 0.88 & 4.21 & 0.63 \\
\hline
\end{tabular}

NB CCS $=$ Christian Community Schools, $\mathrm{F}=$ Female, $\mathrm{M}=$ Male, $\mathrm{pr}=$ private, $\mathrm{pu}=$ public, stu $=$ students, $\mathrm{PER}=$ Personal domain of SWB, COM = Communal domain of SWB, $\mathrm{ENV}=$ Environmental domain of SWB, TRA $=$ Transcendental domain of SWB

Many instruments are developed using university student populations, especially psychology students, because they are often given course credit for participation in research projects, see Table 3. Selection of these students provides a particular bias to research, as does use of other convenience samples.

Table 3. SWB levels among university students using the SWBQ.

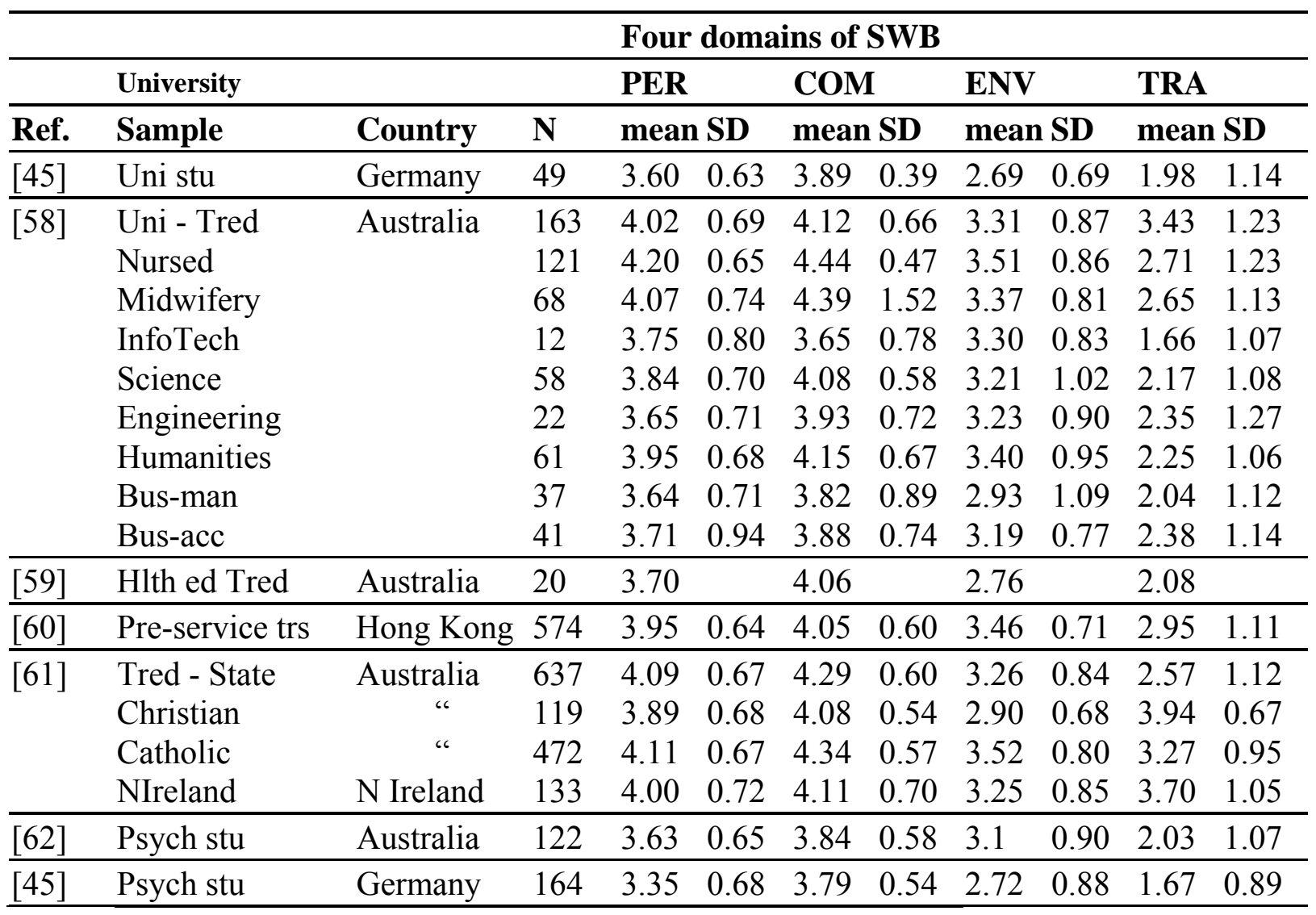

NB (Some studies did not provide SD data), Tred $=$ Teacher education/pre-service teachers, $\mathrm{PER}=$ Personal domain of SWB, $\mathrm{COM}=$ Communal domain of SWB, ENV = Environmental domain of SWB, TRA $=$ Transcendental domain of SWB 
Results from a variety of projects associated with health care, Church, business and general community are shown in Table 4.

Table 4. SWB levels in health care, Churches, business and community using the SWBQ.

\begin{tabular}{|c|c|c|c|c|c|c|c|c|c|c|c|}
\hline & & & & \multicolumn{8}{|c|}{ Four domains of SWB } \\
\hline & & & & \multicolumn{2}{|l|}{ PER } & \multicolumn{2}{|c|}{ COM } & \multicolumn{2}{|l|}{ ENV } & \multicolumn{2}{|l|}{ TRA } \\
\hline \multirow[t]{2}{*}{ Ref. } & Sample & Country & $\mathbf{N}$ & \multicolumn{2}{|c|}{ mean SD } & \multicolumn{2}{|c|}{ mean SD } & \multicolumn{2}{|c|}{ mean SD } & \multicolumn{2}{|c|}{ mean SD } \\
\hline & HEALTH & & & & & & & & & & \\
\hline [63] & Nurses & Australia & 246 & 4.17 & 0.60 & 4.29 & 0.52 & 3.67 & 0.86 & 2.94 & 1.21 \\
\hline \multirow[t]{2}{*}[64]{} & Nurse & \multirow[t]{2}{*}{ Australia } & 210 & 4.15 & 0.66 & 4.26 & 0.56 & 3.74 & 0.85 & 2.96 & 1.25 \\
\hline & Carer & & 15 & 4.41 & 0.44 & 4.31 & 0.40 & 3.93 & 0.55 & 3.76 & 1.35 \\
\hline [65] & PallCare Drs & Australia & 156 & 4.02 & 0.51 & 4.05 & 0.44 & 3.53 & 0.83 & 2.61 & 1.27 \\
\hline \multirow[t]{2}{*}{ [66] } & alcoholics & Canada & 85 & 3.81 & 0.66 & 3.91 & 0.60 & 3.56 & 0.74 & 3.61 & 0.86 \\
\hline & \multicolumn{11}{|l|}{ CHURCH } \\
\hline [67] & church & Australia & 494 & 3.87 & 0.72 & 4.05 & 0.61 & 3.34 & 0.95 & 3.99 & 0.81 \\
\hline [68] & church & UK & 34 & \multicolumn{2}{|l|}{3.61} & \multicolumn{2}{|l|}{3.85} & \multicolumn{2}{|l|}{3.35} & \multicolumn{2}{|l|}{3.49} \\
\hline \multirow[t]{2}{*}{ [69] } & Cathedral visitors & UK & 2695 & \multicolumn{2}{|c|}{$3.59 *$} & \multicolumn{2}{|c|}{$3.79 *$} & \multicolumn{2}{|l|}{$3.51^{*}$} & \multicolumn{2}{|l|}{$2.72 *$} \\
\hline & BUSINESS & & & & & & & & & & \\
\hline [70] & employees & Australia & 316 & 2.03 & 0.64 & 1.95 & 0.57 & 2.28 & 0.82 & 2.88 & 1.11 \\
\hline \multirow[t]{2}{*}{ [71] } & uni staff & Australia & 162 & 3.92 & 0.70 & 4.02 & 0.64 & 3.76 & 0.76 & 2.52 & 1.23 \\
\hline & manufact. industry & & 53 & 3.62 & 0.69 & 3.73 & 0.60 & 3.17 & 0.75 & 2.40 & 1.00 \\
\hline [72] & $\begin{array}{l}\text { business and } \\
\text { education stu }\end{array}$ & Australia & 125 & 4.15 & 0.64 & 4.28 & 0.61 & 3.69 & 0.95 & 2.28 & 1.34 \\
\hline$[73]$ & business executives & Aus & 1179 & 3.82 & 0.68 & 3.85 & 0.61 & 3.27 & 0.78 & 2.62 & 1.16 \\
\hline & & M & 731 & 3.50 & 0.75 & 3.57 & 0.70 & 3.05 & 0.81 & 2.61 & 1.13 \\
\hline & COMMUNITY & & & & & & & & & & \\
\hline$\overline{[74]}$ & $\begin{array}{l}\text { Domestic violence } \\
\text { victims }\end{array}$ & S Africa & 563 & 4.30 & 0.72 & 4.32 & 0.67 & 4.22 & 0.73 & 4.38 & 0.68 \\
\hline [75] & community & Portugal & 237 & 3.81 & 0.57 & 3.70 & 0.55 & 3.59 & 0.76 & 2.88 & 0.95 \\
\hline [45] & community & Germany & 207 & 3.69 & 0.61 & 3.83 & 0.44 & 3.56 & 0.66 & 3.02 & 1.09 \\
\hline
\end{tabular}

NB (Some studies did not provide SD data), * = estimated values extracted from summary results, $\mathrm{PER}=$ Personal domain of SWB, COM = Communal domain of SWB, ENV = Environmental domain of SWB, TRA = Transcendental domain of SWB

Based on Item Response Theory (IRT) analyses of data from a wide spectrum of the community during the development of the SWBQ/SHALOM, an early report suggested potential areas for improvement [39]. It is interesting to note the following attempts in this endeavor (see Table 5). Dehshiri expanded the responses from a 5-point to 6-point Likert scale [76]. Moodley modified items and added new ones [77]. Van Rooyen used this modified SWBQ to report a variety of spiritualities [78]. 
Table 5. Alternate versions of the SWBQ used to assess SWB.

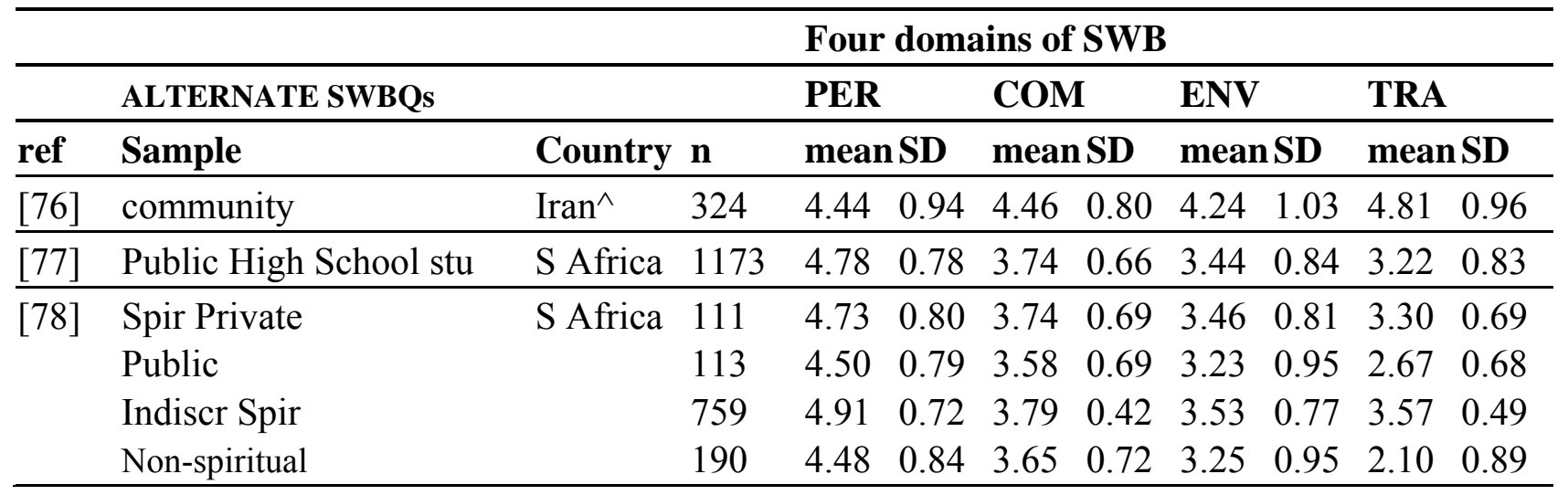

$\mathrm{NB} \wedge$ scale scores 1-6, instead of normal 1-5, Spir = spirituality (e.g., Indiscriminate), PER $=$ Personal domain of SWB COM = Communal domain of SWB, ENV = Environmental domain of SWB, TRA $=$ Transcendental domain of SWB

The two South African graduate students developed this modified version of the SWBQ for use in English and Afrikaans [77,78]. Another South African student was content to use the original in both these languages, plus Xhosa [74]. When developing research instruments it is important not only to choose the item/s with best statistical properties, but also to ensure that the item $/ \mathrm{s}$ fit the theoretical construct underpinning the study. There is some concern with the reported modification of the SWBQ/SHALOM. The items listed in Table 3, p.19 of Moodley [77] comprise six original items, three that reflect the stated changes, eleven that do not correspond to stated changes and six new items. Some of these items are not the same as those reported to be the modified SWBQ in Addendum A (p. 28, [77]), so it is not clear which items have been factor-analyzed. Only analyses using Confirmatory Factor Analysis, but not IRT, have been reported by Moodley, so there is no guarantee that the suggested modifications would hold as well in a general population compared with the more limited, secondary school population studied by Moodley and Van Rooyen.

It is important that items fit the theoretical construct basic to the instrument. The personal domain remains effectively unaltered from the original to the modified form of the SWBQ/SHALOM. In the communal domain, in Item 3, 'connection' replaces 'forgiveness' and in Item 17, 'confidence' replaces 'respect' and in item 19, 'goodwill' replaces 'kindness.' This author considers that forgiveness, respect and kindness are stronger, important expressions of relationships between people, which fit the 4D model of $\mathrm{SH} / \mathrm{WB}$ better and can provide greater insight into pastoral care than the more generic connection, confidence and goodwill. In Item 20, 'magic' in the environment was replaced by fascination. Although the intent of the inverted commas around magic (in the original) was to imply fascination, or wonder, an advantage of using 'magic' is that it helps to identify fundamentalists, who ignore the inverted commas to express a literal view on magic. The change of Item 15 from 'prayer life' to 'prayer enriches my life' changes the meaning of the item substantially to one that is ego-centric away from a more balanced approach to prayer including adoration, confession, thanksgiving and supplication, in relationship with a Transcendent Other.

A 20-item instrument cannot hope to be a perfect measure of SWB for all people. However, the SWBQ/SHALOM has shown it is a valid, reliable 'spiritual thermometer' which provides an indication of SWB among a wide range of people. Changing any feature of the original instrument 
effectively produces a new one, the results from which cannot be compared directly with those from studies employing the original. If anyone wants to improve on the SWBQ/SHALOM, it is recommended that the original 20 items be used, to allow direct comparison with previous research findings, such as those reported in Tables 1-3 above. Additional items can be investigated, using the same 5-point Likert scale, to enrich study in this field.

\section{General Comments on SWBQ Studies}

The studies reported above show that nearly all people are prepared to accept that relationships with themselves and others influence spiritual well-being. These relationships can be positive or negative and quite often it is in dark times that people are thrown onto their inner strength to find answers to meaning, purpose, etc, in life, i.e., personal and communal spiritual pursuits (often referred to as existential [22], humanistic (Spilka cited in [7]), or non-theistic [79]).

Fewer people think about how relating with the environment can enhance spiritual well-being. To some, even suggesting this sounds 'New Age', and some practices are. But, many have 'peak experiences' in special places or events that transcend emotional enjoyment, and enhance spiritual well-being.

The above results show marked divergence of views when relating with a Transcendent Other, often referred to as God, for spiritual well-being. Some people blame God for the hurt they experience from other people, many of whom are religious. So, in an attempt to minimize this hurt by removing the cause, they deny God's existence even though attributing blame to that source. Others believe that humans have the power to understand and solve all challenges by exercising power of the mind, so eliminating the necessity to introduce the notion of a Transcendent Other. We are still waiting to clearly define what the 'mind' is, as well as 'transcendent realities'.

The 1990s were labeled the 'Decade of the Brain' by U.S. Congress. Some hypotheses, conjecture and cautious interpretations of empirical studies suggest that regions of the brain might hold keys to understanding how our spirits relate with self-transcendence and how the brain might have evolved to locate a god-factor. None of this work is definitive and it is all highly influenced by the researchers' world-views. But, it is fascinating reading $[80,81]$

\section{Spiritual Dissonance}

Each person's beliefs and world-view impact their understanding and commitment to the importance of each of the four domains for spiritual health. It is, therefore, important to gain some idea of a person's world-view before attempting to 'measure' their SH/WB. In SHALOM, each person is compared with themselves as their standard. No arbitrary group norms are employed to compare or rank people. The difference between their 'ideals' and how they feel/'lived experience' gives an indication of their SH/WB in each of the four domains. For example, if people do not think relating with the environment is important for SH/WB, when they score 'low' on the 'lived experience' category, this is in harmony with their 'ideals' in this domain of SH/WB, thus not an immediate cause for concern.

Spiritual dissonance is described in the author's work as a marked difference between the ideal and lived experiences in any of the four domains of spiritual well-being indicated by a difference in mean 
values of more than 1.0 on a scale from 1 to 5 . This value is approximately one to two standard deviations in each of the mean values for the four domains of SH/WB. In reported studies, the level of dissonance for secondary school students is close to eight percent in the Personal, Communal and Environmental domains and over 20 percent in the Transcendental domain, with significant variation between school types [52]. Of at least equal, or maybe, greater concern is the finding that similar percentages of teachers show dissonance between their ideals and lived experiences $(12 \%$ Personal, 10\% Communal, 5\% Environmental, 17\% Transcendental) [82].

As teachers' lived experiences are major predictors of how much help they provide to students in schools for SWB [82] this finding has implications for the workplace. Similar findings have been made with nurses [64] and palliative care doctors [65]. These results indicate that how people live influences how much help they give to nurture the SWB of others.

\section{Conclusions}

Few people consider themselves to be spiritually self-sufficient. Most need help to guide them in their search for meaning, purpose and values in life from a personal perspective. And, from a communal perspective, their continuing quest for in-depth relationships with others will build on their personal search, by clarifying and embracing aspects of morality, culture (and religion, among those for whom it is important). This human journey is set in an environment that is teetering on the brink of regression, facing major physical challenges, in terms of energy, finance, global warming, pollution and water shortage, apart from the threat of terrorism and tension between religious groups assailing World peace in hot spots around the globe. How much time they take to embrace the mystical aspects of environmental well-being may well be a moot point. On top of all this, is the perennial question about the existence, or otherwise, of a Divine Creator/Transcendent Other/God, higher power or Ultimate Concern who/that has the potential for an over-arching influence on the quality of relationships and development in the other three (Personal, Communal and Environmental) domains of spiritual health and well-being.

Although no 20-item instrument can hope to capture perfectly the multi-dimensional nature of spiritual well-being, the SWBQ/SHALOM has shown itself to be a valid and reliable instrument for assessing key aspects of the SWB in several languages, across a variety of settings, with different age groups. SHALOM provides a novel means of attaining insight into the quality of relationships in four domains which reflect spiritual well-being by comparing each person's ideals with their lived experience, yielding a measure of spiritual harmony or dissonance in each of the four domains.

It is recommended that future researchers use the SWBQ/SHALOM as it is. Additional questions, which may be added, can be correlated with the four domain scores and/or compared with results from existing studies, such as those reported in this paper. In this way, other research currently in progress and new studies will provide a growing bank of results to help our understanding of spiritual well-being in different cultures and settings. 


\section{References}

1. Johnson, M.E.; Piderman, K.M.; Sloan, J.A.; Huschka, M.; Atherton. P.J.; Hanson, J.M.; Brown, P.D.; Rummans, T.A.; Clark, M.M.; Frost, M.H. Measuring Spiritual Quality of Life in Cancer Patients. J. Support. Oncol. 2007, 5, 437-442.

2. Cummins, R.A. Australian Unity Wellbeing Index Survey 19. Available online: http://www.deakin.edu.au/research/acqol/index_wellbeing/index.htm (accessed on 16 October 2008).

3. Good, M.; Willoughby, T. The role of spirituality versus religiosity in adolescent psychosocial adjustment. J. Youth Adolesc. 2006, 35, 41-55.

4. Hill, P.C.; Hood, R.W. Measures of Religiosity; Religious Education Press: Birmingham, AL, USA, 1999.

5. Koenig, H.G.; McCullough, M.E.; Larson, D.B. Handbook of Religion and Health; Oxford University Press: Oxford, UK, 2001.

6. MacDonald, D.A.; Friedman, H.L. Assessment of Humanistic, Transpersonal, and Spiritual Constructs: State of the Science. J. Human Psychol. 2002, 42, 102-125.

7. Moberg, D.O. Assessing and Measuring Spirituality: Confronting Dilemmas of Universal and Particular Evaluative Criteria. J. Adult Dev. 2002, 9, 47-60.

8. Hill, P.C.; Pargament, K.I. Advances in the Conceptualization and Measurement of Religion and Spirituality. Am. Psychol. 2003, 58, 64-74.

9. Egbert, N.; Mickley, J.; Coeling, H. A Review and Application of Social Scientific Measures of Religiosity and Spirituality: Assessing a Missing Component in Health Communication Research. Health Commun. 2004, 16, 7-27.

10. King, J.E.; Crowther, M.R. The measurement of religiosity and spirituality. J. Org. Change 2004, 17, 83-101.

11. Roehlkepartain, E.C.; Benson, P.L.; Scales, P.C.; Kimball, L.; King, P.E. With Their Own Voices: A Global Exploration of How Today's Young People Experience and Think about Spiritual Development; Search Institute: Minneapolis, MN, USA, 2008.

12. Berry, D. Methodological Pitfalls in the Study of Religiosity and Spirituality. West. J. Nurs. Res. 2005, 27, 628-647.

13. Zinnbauer, B.J.; Pargament, K.I.; Scott, A.B. The Emerging Meanings of Religiousness and Spirituality: Problems and Prospects. J. Personal. 1999, 67, 889-919.

14. Hill, P.C.; Pargament, K.I.; Hood, R.W.; McCullough, J.P.; Swyers, D.B.; Larson, D.B.; Zinnbauer, B.J. Conceptualizing Religion and Spirituality: Points of Commonality, Points of Departure. J. Theory Soc. Behav. 2000, 30, 51-77.

15. Benson, P.L. Emerging Themes in Research on Adolescent Spiritual and Religious Development. Appl. Dev. Sci. 2004, 8, 47-50.

16. McCarroll, P.; O’Connor, T.; Meakes, E. Assessing Plurality in Spirituality Definitions. In Spirituality and Health: Multidisciplinary Explorations; Meier, A., O’Connor, T., Van Katwyk, P.L., Eds.; Wilfrid Laurier University Press: Waterloo, Canada, 2005; pp. 43-61.

17. Buck, H.G. Spirituality: Concept Analysis and Model Development. Holist. Nurs. Pract. 2006, 20, 288-292. 
18. Gray, J. Measuring Spirituality: Conceptual and Methodological Considerations. J. Theory Construct. Test. 2006, 10, 58-64.

19. Ross, L. Spiritual care in nursing: An overview of the research to date. J. Clin. Nurs. 2006, 15, 852-862.

20. Boero, M.; Caviglia, M.; Monteverdi, R.; Braida, V.; Fabello, M.; Zorzella, L. Spirituality of health workers: A descriptive study. Int. J. Nurs. Stud. 2005, 42, 915-921.

21. Fisher, J.W. Spiritual Health: its Nature and Place in the School Curriculum. PhD thesis, University of Melbourne, 1998. Available from http://eprints.unimelb.edu.au/archive/00002994/, Melbourne University Custom Book Centre: Melbourne, Australia, 2010.

22. Ellison, C. Spiritual well-being: Conceptualization and measurement. J. Psychol. Theol. 1983, 11, 330-340.

23. Ledbetter, M.F.; Smith, L.A.; Fischer, J.D.; Vosler-Hunter, W.L.; Chew, G.P. An evaluation of the construct validity of the Spiritual Well-Being Scale: A confirmatory factor analytic approach. J. Psychol. Theol. 1991, 19, 94-102.

24. Gow, A.J.; Watson, R.; Whiteman, M.; Deary, I.J. A stairway to heaven? Structure of the Religious Involvement Inventory and Spiritual Well-Being Scale. J. Relig. Health 2010, doi: 10.1007/s10943-010-9375-2.

25. Scott, E.L.; Agresi, A.A.; Fitchett, A. Factor analysis of the 'Spiritual Well-Being Scale' and its clinical utility with psychiatric inpatients. J. Sci. Stud. Relig. 1998, 37, 314-321.

26. Koenig, H.G. Concerns about measuring “spirituality" in research. J. Nerv. Ment. Dis. 2008, 196, 349-355.

27. Fehring, R.; Miller, J.; Shaw, C. Spiritual well-being, religiosity, hope, depression, and other mood states in elderly people coping with cancer. Oncol. Nurs. Forum 1997, 24, 663-671.

28. National Interfaith Coalition on Aging. Spiritual Well-Being: A Definition; NICA: Athens, GA, USA, 1975.

29. Burkhardt, M.A. Spirituality: An analysis of the concept. Holist. Nurs. Pract. 1989, 3, 69-77.

30. Como, J.M. A Literature Review Related to Spiritual Health and Health Outcomes. Holist. Nurs. Pract. 2007, 21, 224-236.

31. Martsolf, D.S.; Mickley, J.R. The concept of spirituality in nursing theories: Differing worldviews and extent of focus. J. Adv. Nurs. 1998, 27, 294-303.

32. Tillich, P. Systematic Theology, Volume III: Life and the Spirit History and the Kingdom of God; University of Chicago Press: Chicago, IL, USA, 1967.

33. Fisher, J.W. Reaching the heart: Assessing and nurturing spiritual well-being via education. EdD dissertation, University of Ballarat, Victoria, Australia, 2009. Available from http://archimedes.ballarat.edu.au:8080/vital/access/HandleResolver/1959.17/13481, Melbourne University Custom Book Centre: Melbourne, Australia, 2010.

34. Fisher, J.W.; Francis, L.J.; Johnson, P. Assessing spiritual health via four domains of well-being: The SH4DI. Pastoral Psychol. 2000, 49, 133-145.

35. Fisher, J.W. Comparing levels of spiritual well-being in State, Catholic and Independent schools in Victoria, Australia. J. Beliefs Values 2001, 22, 113-119.

36. BibleRick. http://abibleconcordance.com/40H-7900.htm\#7965 (accessed on 10 August 2010). 
37. Fisher, J.W. Helps to fostering students' spiritual health. Int. J. Children's Spiritual. 1999, 4, $29-49$.

38. Gomez, R.; Fisher, J.W. Domains of spiritual well-being and development and validation of the Spiritual Well-Being Questionnaire. Pers. Indiv. Differ. 2003, 35, 1975-1991.

39. Gomez, R.; Fisher, J.W. Item Response Theory analysis of the Spiritual Well-Being Questionnaire. Pers. Indiv. Differ. 2005, 38, 1107-1121.

40. Gomez, R; Fisher, J.W. The Spiritual Well-Being Questionnaire: Testing for model applicability, measurement and structural equivalencies and latent mean differences across gender. Pers. Indiv. Differ. 2005, 39, 1383-1393

41. Moberg, D.O. Subjective measures of spiritual well-being. Rev. Relig. Res. 1984, 25, 351-364.

42. Piedmont, R.L. Spiritual Transcendence and the Scientific Study of Spirituality. J. Rehabil. 2001, 67, 4-14.

43. Salandar, P. Who needs the concept of 'spirituality'? Psycho-Oncology 2006, 15, 647-649.

44. Tsuang, M.T.; Simpson, J.C.; Koenen, K.C.; Kremen, W.S.; Lyons, M.J. Spiritual well-being and health. J. Nerv. Ment. Dis. 2007, 195, 673-680.

45. Rowold, J. Effects of spiritual well-being on subsequent happiness, psychological well-being, and stress. J. Relig. Health. 2010, doi: 10.1007/s10943-009-9316-0.

46. Burkhardt, M.A.; Nagai-Jacobson, M.G. Reawakening spirit in clinical practice. J. Holist. Nurs. 1994, 12, 9-21.

47. MacLaren, J. A kaleidoscope of understandings: Spiritual nursing in a multi-faith society. J. Adv. Nurs. 2004, 45, 457-464.

48. Thatcher, A. A critique of inwardness in Religious Education. Br. J. Relig. Educ. 1991, 14, 22-27.

49. Hungelmann, J.; Kenkel-Rossi, E.; Klassen, L.; Stollenwerk, R. Spiritual well-being in older adults: harmonious inter-connectedness. J. Relig. Health. 1985, 24, 147-153.

50. de Jager Meezenbroek, E.; Garssen, B.; van den Berg, M; van Dierendonck, D. et al. Measuring spirituality as a universal human experience: A review of spirituality questionnaires. J. Relig. Health. 2010, doi: 10.1007/s10943-010-9376-1.

51. Fisher, J.W. Developing a Spiritual Health And Life-Orientation Measure for secondary school students. In Research with a regional/rural focus: Proceedings of the University of Ballarat inaugural annual research conference; Ryan, J., Wittwer V., Baird, P., Eds.; University of Ballarat, Research and Graduate Studies Office: Ballarat, Australia, 1999; pp. 57-63.

52. Fisher, J.W. Using secondary students' views about influences on their spiritual well-being to inform pastoral care. Int. J. Children's Spiritual. 2006, 11, 347-356.

53. Holder, M.D.; Coleman, B.; Wallace, J.M. Spirituality, religiousness, and happiness in children aged 8-12 years. J. Happiness Stud. 2010, 11, 131-150.

54. Moore, K. Master's degree Candidate, Department of Educational and Counselling Psychology, McGill University, Montreal. Private communication, 2010.

55. Leaver, L. Spiritual Development in Adolescence; Can it Be Measured? Can it Be Increased? Available online: http://www.farmington.ac.uk/documents/new_reports/PS59.pdf (Accessed on 17 August 2010).

56. Wong, P.H.; Fisher, J.W. Assessing the spiritual well-being of pre-school teachers in Hong Kong. Private communication, 2010. 
57. Fisher, J.W. It's time to wake up and stem the decline in spiritual well-being in Victorian schools. Int. J. Children's Spirituality 2007, 12, 165-177.

58. Fisher, J.W. Tertiary students' career choice and SHALOM. Paper presented at the International Seminar on Religious Education and Values (ISREV XII), Israel, 23-28 July 2000.

59. Deagon, J.R. Pre-service teachers' attitudes and beliefs about spiritual health and wellbeing and their university experience. MEd, Survey research report, Griffith University, Mt Gravatt, Queensland, Australia, 2009.

60. Wong, P.H.; Fisher, J.W. Using SHALOM to assess the spiritual well-being of pre-service teachers in Hong Kong. Private communication, 2010.

61. Fisher, J.W.; Barnes, L.P.; Marks, G. Pre-service teachers' spiritual well-being across time and faiths: Implications for religious education. Relig. Educ. J. Aust. 2009, 25, 10-16.

62. Stott, A. The relationship of spiritual well-being to other measures of subjective well-being. Postgrad. Dip Psych. dissertation, Department of Psychology, University of Ballarat, Australia, 2002.

63. Lea, D.M. Spiritual awareness of professional nurses in the Western region of Victoria: Investigation of a significant component of holistic health care. MNurs. dissertation, School of Nursing, University of Ballarat, Australia, 2005.

64. Fisher, J.W.; Brumley, D.J. Nurses' and carers' spiritual well-being in the workplace. Aust. J. Adv. Nurs. 2008, 25, 49-57.

65. Fisher, J.W.; Brumley, D.J. When it comes to spiritual well-being, palliative care doctors are different. At Australian \& New Zealand Society for Palliative Medicine Conference, Darwin, Australia, 23-6 September 2008.

66. Streukens, J.P. Alcoholism: Spirituality and personality dynamics. PhD dissertation, Faculty of Graduate Studies, University of Calgary, Alberta, Canada, 2009.

67. Fisher, J.W. An investigation of spiritual well-being among people who attend Christian churches in Ballarat. Private communication, 2010.

68. Doores, P. G. Modelling spirituality: A critical examination of the value of models of spirituality as a basis for encouraging spiritual growth in a Christian church community. M.A thesis, Oxford Brookes University, Oxford, UK, 2004.

69. Brice-Annis, J. The soul of St David's: Mapping the spiritual quest of visitors to St David's Cathedral. $\mathrm{PhD}$ thesis, Institute of Education, University of Warwick, 2010.

70. Becker, P.L. Spirituality in Australian organizations employee attitudes and impact on well being. D Psychol. Dissertation, Swinburne University of technology, Victoria, Australia, 2002.

71. Fisher, J.W.; Sellers, E.T. Quality of life in the workplace: Spirituality, meaning and purpose. Refereed paper in the Proceedings of the 3rd Annual Conference on Spirituality, Leadership and Management, University of Ballarat, Australia, 2000; pp. 14-19.

72. Hall, H. How the domains of spiritual well-being predict current quality of life and general wellbeing. Post-grad. Dip Psych. dissertation, Department of Psychology, University of Ballarat, Australia, 2005.

73. Fernando, M.; Chowdhury, R.M. The relationship between spiritual well-being and ethical orientations in decision making: An empirical study with business executives in Australia. J. Bus. Ethics 2010, doi: 10.1007/s10551-009-0355-y. 
74. Vogt, T. The impact of an Interim Protection Order (Domestic Violence Act 116 of 1998) on the victims of domestic violence. D Pyschol. Dissertation, University of Stellenbosch, South Africa, 2007.

75. Gouveia, M.J.; Pais Ribeiro, J.; Marques, M. Adaptação Portguesa do Questionário de Bem Espiritual: resultados psicométricos preliminares. In Actas do $7^{\circ}$ Congresso Nacional de Psicologia da Saúde, Leal, I., Pais-Ribeiro, J., Silva, I., Marques, S., Eds.; ISPOA: Lisboa, Portugal, 2008; pp. 423-426.

76. Dehshiri, G.R. Using the SWBQ to investigate community in Iran. Private communication, 2010.

77. Moodley, T. The relationship between coping and spiritual well-being during adolescence. $\mathrm{PhD}$ disertation, Department of Psychology, University of the Free State, Bloemfontein, South Africa, 2008.

78. Van Rooyen, B.M. Spiritual well-being in a group of South African adolescents. PhD dissertation, Department of Psychology, University of the Free State, Bloemfontein, South Africa, 2007.

79. Haber, J.R.; Jacob, T.; Spangler, D.J.C. Dimensions of Religion/Spirituality and Relevance to Health Research. Int. J. Psychol. Relig. 2007, 17, 265-288.

80. Hamer, D. The God Gene: How Faith is Hardwired into Our Genes; Doubleday: New York, NY, USA, 2004.

81. Beauregard, M.; O'Leary, D. The Spiritual Brain: A Neuroscientist's Case for the Existence of Soul; Harper Collins: New York, NY, USA, 2007.

82. Fisher, J.W. Impacting teachers' and students' spiritual well-being. J. Beliefs Values 2008, 29, 252-261.

(C) 2010 by the authors; licensee MDPI, Basel, Switzerland. This article is an open access article distributed under the terms and conditions of the Creative Commons Attribution license (http://creativecommons.org/licenses/by/3.0/). 